\title{
Outcome of fallopian tube recanalization
}

\author{
Jageshwor Gautam \\ Dept.of Obstetrics\& Gynaecology \\ Bharatpur Hospital, Chitwan, Nepal
}

\begin{abstract}
Objective: To find out the fertility outcome of tubal surgery.

Method: This was a hospital based descriptive study conducted at Om Hospital, Bharatpur. Forty-one women who were operated in this hospital during the period of 6 years. (Jan 2002- December 2007).

Results: Of 41 patients who underwent tuboplasty, 34 (82.9\%) cases were available for follow-up. Out of these 34 cases, 14 (41.2\%) became pregnant. Among them 9 (64.3\%) had viable births, 3 (21.4\%) ectopic pregnancies and 2 (14.3\%) spontaneous miscarriages.

Conclusion: Fallopian tube recanalization has been established as an effective, useful and novel treatment of infertility due to tubal occlusion.
\end{abstract}

Key words: Infertility, fallopian tube, tuboplasty, pregnancy.

\section{Introduction}

Tubal disease accounts for $25-35 \%$ of infertility in woman and salpingitis is believed to account for more than $50 \%$ of these cases. ${ }^{1}$ Approximately $1 \%$ of women who undergo surgical sterilization seek reversal of the procedure. ${ }^{2}$ A wide variety of techniques has been developed in recent years. Macro and microsurgical techniques, laparoscopic and falloposcopic recanalization, balloon tuboplasty, hysteroscopic cannulation of fallopian tube and combined techniques are being performed at present all over the world.

Direction towards one treatment or another depends on a variety of factors including the severity of the tubal pathology and the availability IVF or microsurgery. ${ }^{3}$ With the shift away from microsurgical training, the treatment trend appears to be increasingly towards IVF; however, surgery is still the preferred choice of treatment for selected cases in specialist microsurgical units. ${ }^{4}$ Reconstructive surgery for proximal tubal diseases is more than 100 years old. The first successful case of uterotubal implantation, calling the procedure "Metrosalpingo anastomosis", was done in $1896 .{ }^{5}$ In contrast to the development of techniques, little attention has been given to surgical correction of tubal infertility. Although surgical correction of tubal blockage is invasive, cumbersome and highly skilled operative treatment, there is still valid justification of this operation in underdeveloped countries where IVF is not affordable to average people. As $14 \%$, cases of infertility are due to tubal factors, tuboplasty can be an alternative of IVF-ET.

\section{Methods}

Forty-one patients of infertility due to tubal diseases and tubal sterilization were selected for operation. Different variables like age, race, history of previous fertility outcome and illness, duration of infertility, history of tubal sterilization, reason for recanalisation, contact address and telephone number were enquired and documented.

The tubal occlusion was diagnosed by the history of tubal sterilization, hysterosalpingography and

Correspondence

Dr. Jageshwor Gautam. MBBS, MD,

Consultant Obstetrician \& Gynaecologist

Deparment of Obstetrics \& Gynaecology, Bharatpur, Chitwan, Nepal

E-mail:drjgautam@hotmail.com 
diagnostic laparoscopy. Patients with cornual block and more than 40 years of age, were excluded. Option was given to choose either IVF or tuboplasty. Patients interested to undergo tuboplasty were investigated for surgery. The surgical procedure was performed under nacked eye or magnifying loop. The site of occlusion was identified by instillation of diluted methylene blue from uterus or distal end of fallopian tube.

Tubal anastomosis was performed bilateraly in all cases. A two-layer closure using 6 'o' prolene was performed. Tissue handling was atraumatic, and tissues were kept moist at all times by saline irrigation. Unipolar electrocoagulation was always used for hemostasis.

Before final closure of the peritoneum $100 \mathrm{ml}$ of Ralidex in normal saline was placed in the pelvic cavity. Prophylactic antibiotics were given postoperatively, but postoperative hydrotubation was not done.

Skin stitches were taken out on $5^{\text {th }}$ postoperative day and discharged from hospital. Patinas were followed up to find out the outcome.

\section{Results}

The clinical profile of 41 patients undergoing tubal surgry was reviewed. At the time of surgery, the mean age ( \pm ISD) was $27.6 \pm 5.1$ years (range 18 -39 years). The mean duration of infertility was 8.2 years (range $1-20$ years). Ten cases $(29.4 \%)$ had tubal occlusion due to female sterilization (minilap-6, laparoscopic tubal ligation-2 and post partum tubal ligation-2), whereas $24(70.6 \%)$ cases had tubal block due to other tubal diseases. Table 1 is given bellow.

Table I. Overall outcome of tuboplasty

\begin{tabular}{lcc}
\hline Outcome parameter & Frequency & percentage \\
\hline Failure to conceive & 20 & 58.82 \\
Viable Births & 9 & 26.47 \\
Ectopic Pregnancy & 3 & 8.82 \\
Miscarriage & 2 & 5.88 \\
\hline Total & 34 & 100.00 \\
\hline
\end{tabular}

Table 2. Types of operation and success.

\begin{tabular}{lccc}
\hline \multirow{2}{*}{$\begin{array}{l}\text { Outcome } \\
\text { Parameters }\end{array}$} & \multicolumn{2}{c}{ No. of cases } & \\
\cline { 2 - 3 } & $\begin{array}{c}\text { Reversal } \\
\text { of TL }\end{array}$ & Tuboplasty & Total \\
\hline Failure to conceive & 6 & 14 & 20 \\
Pregnancy & 4 & 10 & 14 \\
\hline Total & 10 & 24 & 34 \\
\hline
\end{tabular}

Out of 34 cases followed up during study period, $14(41.2 \%)$ cases became pregrant. Among them 9 (64.3 $\%)$ had viable births, $3(21.4 \%)$ ectopic pregnancy and 2 (14.3) miscarriage. Twenty $(58.8 \%)$ cases failed to conceive and they are still under follow up .

The reasons for reversal of tubal sterilization were loss of babies in six cases and remarriage in four cases. Two cases became pregnant twice and delivered fullterm babies after reversal. The pregnancy between reversal of tubal sterilization $(\mathrm{n}=10)$ and tuboplasty for other disceases $(n=24)$ was not statistically significant $\left(x 2^{\text {test }} \mathrm{p}>.05\right)$ (Table 2$)$.

Out of 10 cases in sterilization reversal group, 4(40\%) cases had viable births and 6(60\%) cases did not conceive. There was no case of abortion and ectopic pregnancy. Among 24 cases of tuboplasty for tubal disease $10(41.7 \%)$ cases conceived. Out of them 5(50\%) cases had viable births, $3(30 \%)$ ectopic pregnancy and $2(20 \%)$ abortions (Table 3 ).

\begin{tabular}{lccc}
\hline \multirow{2}{*}{$\begin{array}{l}\text { Outcome } \\
\text { Parameters }\end{array}$} & \multicolumn{2}{c}{ No. of cases } & \\
\cline { 2 - 3 } & $\begin{array}{c}\text { Reversal } \\
\text { of }\end{array}$ & Tuboplasty & Total \\
\hline Failure to conceive & 6 & 14 & 20 \\
Viable births & 4 & 5 & 9 \\
Ectopic pregnancy & - & 3 & 3 \\
Miscarriage & - & 2 & 2 \\
\hline Total & 10 & 24 & 34 \\
\hline
\end{tabular}

\section{Discussion}

The study was undertaken to give a glance of success of tuboplasty surgery done in a hospital outside Kathmandu valley. There has been a tremendous increase in the rate of female sterilization and tubal diseases in recent years. Increasing number of patients require either surgical correction or IVF-ET. Because of high cost of IVF-ET, average people can't afford for the treatment.

The reason for reversal of tubal sterilization is loss of children comprising $60 \%$ of total requests; which is similar $(50.8 \%)$ to that mentioned by Seok Hyan Kim et al. ${ }^{6}$ The overall pregnancy rate after tuboplasty is $41.2 \%$ in this study that is less as compared to $55 \%$ shown by Seok Hyon Kim et all ${ }^{6}$. Reported results of tubal anastomosis surgery may be skewed. Experienced physicians have published cumulative pregnancy rates of upto $70 \%$, with an ectopic pregnancy rate of $2 \%$. 
Different pregnancy rates associated with different methods of tubal sterilization, remaining length of tube after tuboplasty, age of the patients, degree of tissue destruction and quality of semen are documented by different authors. ${ }^{7,8,9}$ The health of the remaining tubal segment seems to be important to the overall success of procedure. The success of surgical tubal anastomosis is directly linked to surgical experience. With the advent of ART, surgical training has markedly declined. One study reported that current fellows in Reproductive Endocrinology performed $<10$ procedures and $35 \%$ of program graduates performed no surgical tubal reversal and $54 \%$ graduates reported that tuboplasty has little to no importance in their clinical practice. ${ }^{10}$

The clinical dilemma is how to predict who is likely to conceive. This is a small study which may not be able to explain why pregnancy rate is low and ectopic pretnancy rate is high. The follow up duration varied. Success rate may be higher if these cases were followed up farther in the future. A large study in the future can show detailed aspects and success of tubal surgery.

\section{Conclusion}

The tubal recanalization in selected cases is cost effective treatment. As compared to IVF-ET, tubal surgery is affordable, feasible and less expensive. Results are better with experienced hands and better operative facilities.

\section{References}

1. Gerard M. Honore, Alan E. C. Holden, Robert S. Schenken. Pathophysiology and management of proximal tubal blockage. Fertility and sterility 1999;71:785-95
2. Michael J. Slowey, Charles C. Coddington. Microsurgical tubal anastomoses performed as an outpatient procedure. Fertility and sterility 1998;69:492-5

3. Hull MGR, Fleming CF. Tubal surgery versus assisted reproduction: assessing their role in infertility therapy. Curr Opinion Obstet Gynecol 1995;7:160-7

4. Novy MJ. Tubal Surgery of IVF-making the best choice in the 1990s. Int J Fertility 1995; 40:291302

5. Siegler A, Hellman L. Tubal platic surgery. Fertility sterility 1956;7:170-7

6. Seok Hyun Kim, Shin Yong Moon et al. Microsurgical reversal of tubal sterilization. Fertility sterility 1997;68:865-70

7. Seiler JC. Factor influencing the outcome of microsurgical ligation reversals. Am J Obstet Gynecol 1983;46:292-8

8. Henderson SR. The reversibility of female sterilization with the use of microsurgery; a report of 102 patients with more than one year followup Am Jobstet Gynecol 1984;149:57-65

9. Meldrum DR Microsurgical reversal of tubal reanastomosis, the role of splint. Obstet Gynecol 1981;57:613-9

10. Armstrong A, Neithardt AB, Alvero R, Sharara FI, Bush M, Segars J. The role of fallopian tube anastomosis in training fellows; a survery of current reproductive endocrinology fellow and practitioners. Fertility sterility 2004;82: 495-7. 